\title{
How much does screening bring forward the diagnosis of type 2 diabetes and reduce complications? Twelve year follow-up of the Ely cohort
}

\author{
M. Rahman • R. K. Simmons • S. H. Hennings • \\ N. J. Wareham • S. J. Griffin
}

Received: 3 June 2011 / Accepted: 7 December 2011 /Published online: 12 January 2012

(C) Springer-Verlag 2012

\begin{abstract}
Aims There are continuing uncertainties about how much screening for type 2 diabetes brings forward the clinical diagnosis and the impact that earlier diagnosis has on health outcomes. We compared the duration of diabetes and health outcomes in a population invited for diabetes screening at 5yearly intervals from 1990 (screened population) with those in a similar population not invited for screening (unscreened population).

Methods This was a parallel-group, cohort study of people aged 40-65 years, free of known diabetes, identified from the population register of a general practice in Ely, Cambridgeshire, UK $(n=4,936)$. In 1990-1992, one-third $(n=1,705)$, selected randomly, received an invitation for screening for diabetes and cardiovascular risk factors at 5-yearly intervals (screened population). From the remainder of the sampling frame, 1,705 randomly selected individuals were invited to diabetes screening 10 years later (unscreened population). Patients with diabetes from both populations were invited for a health assessment, including biochemical, anthropometric and questionnaire measures, and testing for the presence of diabetic complications

Results Of the 199 eligible individuals with diabetes diagnosed during follow-up, $152(76 \%)$ attended for health assessment. The median duration of clinically recognised diabetes
\end{abstract}

\section{Rahman}

General Practice and Primary Care Research Unit,

University of Cambridge,

Cambridge, UK

R. K. Simmons · S. H. Hennings • N. J. Wareham •

S. J. Griffin $(\bowtie)$

MRC Epidemiology Unit, Institute of Metabolic Science,

Box 285, Addenbrooke's Hospital, Hills Road,

Cambridge CB2 0QQ, UK

e-mail: simon.griffin@mrc-epid.cam.ac.uk was significantly longer in cases arising in the screened (5.0 years) compared with the unscreened population (1.7 years; $p=0.006$ ). Clinical measures, prescribed medication and functional status were similar between screened and unscreened populations.

Conclusions Diabetes screening resulted in cases being identified on average 3.3 years earlier, a difference significantly shorter than previous estimates. Earlier diagnosis did not appear to impact on health outcomes. Further evidence is needed to justify the introduction of population-based screening.

Keywords Diabetes $\cdot$ Ely $\cdot$ Health outcomes $\cdot$ Screening

$\begin{array}{ll}\text { Abbreviations } \\ \text { ABPI } & \text { Ankle-brachial pressure index } \\ \text { ACR } & \text { Albumin to creatinine ratio } \\ \text { CVD } & \text { Cardiovascular disease } \\ \text { EQ } & \text { EuroQol } \\ \text { GP } & \text { General practitioner } \\ \text { IHD } & \text { Ischaemic heart disease } \\ \text { IQR } & \text { Interquartile range } \\ \text { MI } & \text { Myocardial infarction } \\ \text { NPDR } & \text { Non-proliferative diabetic retinopathy } \\ \text { SF } & \text { Short form } \\ \text { TC } & \text { Total cholesterol }\end{array}$

\section{Introduction}

Type 2 diabetes is increasingly common and creates a substantial burden of suffering and health service use [1]. A growing body of evidence suggests that earlier detection and treatment of diabetes might be beneficial [2]. Screen-detected 
patients have high levels of modifiable cardiovascular risk and thus have the potential to benefit from early intervention [3]. There is some evidence of benefit associated with general health or cardiovascular disease risk screening in populationbased samples. Participants randomised to general practitioner (GP)- or nurse-led interventions focusing on lifestyle factors have demonstrated modest reductions in cardiovascular risk scores and risk factors over $1[4,5]$ and 5 years, respectively [6]. Furthermore, screening does not appear to be associated with psychological harm [7].

While modelling studies suggest that screening may be an efficient use of resources [8], and diabetes screening has been advocated by a number of organisations, there are several outstanding uncertainties [2]. One of these is the duration of the latent period, or lead time, by which screening brings forward the diagnosis of diabetes. In 1992 Harris and colleagues extrapolated data on the relationship between retinopathy and duration of diabetes and concluded that the true onset of disease was likely to be 9-12 years prior to the point of clinical detection [9]. The length of the lead time is important for policy decisions about whether or not to screen for diabetes, as, in general, the benefits of screening will lessen as lead time shortens. It is possible that lead time could vary between secular periods if clinical vigilance and increased testing led to earlier diagnosis of suspected cases. We therefore sought to quantify the extent to which screening brought forward the diagnosis of diabetes and to estimate the impact of earlier diagnosis on 12-year health outcomes in patients with diabetes from a screened and unscreened group from the same population.

\section{Methods}

Study design The Ely Study (Cambridgeshire, UK) was established in 1990 as a prospective cohort study of the aetiology of type 2 diabetes. Full details of the study are reported elsewhere $[10,11]$. In brief, a third $(n=1,705)$ of all men and women aged 40-65 years were randomly selected from a sampling frame of adults free of known diabetes registered with a single practice serving Ely $(n=4,936)$. Housebound individuals were excluded prior to invitation. Individuals were invited between 1990 and 1992 for screening for type 2 diabetes with a $75 \mathrm{~g}$ OGTT and for related cardiovascular risk factors (cholesterol, blood pressure, $\mathrm{HbA}_{1 \mathrm{c}}$, BMI) (the 'screened' population). This group were invited for identical screening measurements at a median of 4.5 years (1994-1996) and 10 years (2000-2003), including invitation to non-attenders at baseline (Fig. 1). At each screening round, GPs were informed by letter of participants' fasting plasma cholesterol and triacylglycerol values, blood pressure and the results of the OGTT. Among the remaining two-thirds of the sampling frame who were still alive in 2000-2003, a retrospective decision was made randomly to select 1,705 individuals using an SPSS random number function for invitation to a health assessment, including an OGTT (the 'unscreened' population). No standard intervention package was specified for people found to have type 2 diabetes or elevated cardiovascular risk factors following screening. GPs were informed of the results and advised to take whatever action they thought necessary. Standard WHO thresholds were used to assess diabetes status throughout the study period, i.e. fasting venous value $\geq 7.0 \mathrm{mmol} / 1$ and/or $2 \mathrm{~h}$ post glucose load venous value $\geq 11.1 \mathrm{mmol} / 1$. This extension to the original Ely study was approved by the Cambridge Local Research Ethics Committee (99/246). All participants gave their written informed consent.

Material deprivation Postcodes were available for $90 \%$ of participants and were linked to enumeration districts to calculate the Townsend Index-a composite measure of material deprivation based on four factors derived from the 1991 UK census (unemployment, overcrowding, car ownership and home ownership). The index is a standardised $\mathrm{z}$ score: a score above 0 implies that deprivation is greater than the mean for England and Wales, while a score below 0 indicates less deprivation [12].

Health assessment visit In order to assess the potential impact of screening on health outcomes, all individuals from both the screened and unscreened populations who were still alive in 2000 received a postal invitation asking them to state whether they had diabetes and if they would agree to attend for a health assessment visit. Invitation was restricted to those still registered at the practice. Those who did not reply were telephoned and invited to attend. Those unable to attend the testing centre were offered a home visit, and those unable to visit due to ill health were classified as nonattenders. Those unable or unwilling to attend for testing were asked if they would fill in a postal questionnaire.

Participants were asked to attend a local testing centre (Princess of Wales Hospital, Ely), where they underwent an examination that included biochemical, anthropometric and questionnaire measures, as well as testing for the presence of diabetic complications. Measures were undertaken by centrally trained staff following standard operating procedures. The staff were unaware of the study group status.

Clinical characteristics Blood pressure was calculated as the mean of three measurements taken 1 min apart, while participants were seated with the cuff on the right arm, using an automatic sphygmomanometer (Accutor; Datascope Medical, Huntingdon, UK). Height and weight were measured in light indoor clothing, without shoes, using a fixed rigid stadiometer and a Seca scale, respectively. Percentage body fat was measured with the impedance method using 


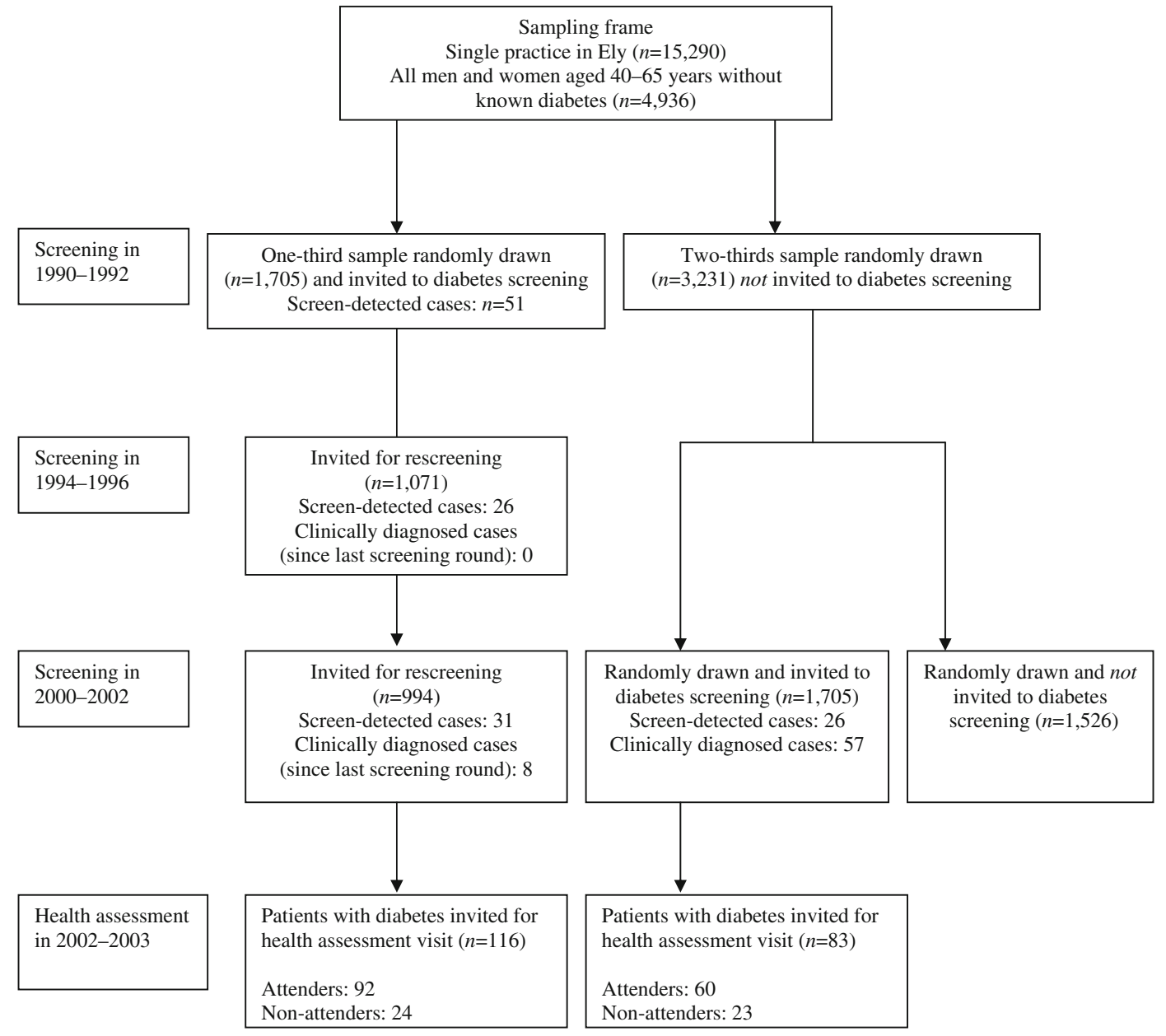

Fig. 1 The Ely study population

the Bodystat 1500 body fat monitor (Bodystat, Isle of Man, British Isles). A non-fasting sample of venous blood was taken for assessment of total cholesterol (TC), HDL-cholesterol and glycosylated haemoglobin; a urine sample was taken for assessment of albumin/creatinine ratio (ACR). All biochemical samples were tested at Addenbrooke's Hospital, Cambridge, using standard methods [10].

Prescribed medication The self-report questionnaire included items asking about currently prescribed medication.

Peripheral vascular disease Ankle-brachial pressure index (ABPI) was assessed with a mercury sphygmomanometer (Accoson Dekamet; Accoson, London, UK) to measure the systolic pressure three times in the upper arm and three times at the ankle. A handheld Doppler probe (Huntleigh Diagnostics, Cardiff, UK) was placed over the brachial artery of the right arm to obtain an arterial pulse signal and on the dorsum of the foot to identify the dorsalis pedis pulse; if this was not possible, the posterior tibial pulse was used. An average of three readings was used to define ABPI.
Peripheral vascular disease was defined as an ABPI $<0.9$, a threshold used in clinical practice that has been shown to have greater than $90 \%$ sensitivity and specificity in symptomatic disease with demonstrable arterial narrowing on angiography [13].

Peripheral neuropathy Peripheral neuropathy was assessed with a biothesiometer (Vibrameter ${ }^{\circledR}$; Somedic, Hörby, Sweden), a 10 g Semmes-Weinstein monofilament (Timesco, London, UK), a thermal testing instrument (Tip Therm, Düsseldorf, Germany) and a modified version of the questionnaire from the Michigan Screening Instrument [14]. Neuropathy was defined using the following criteria: a score of less than nine out of ten using the monofilament, which was applied five times on the dorsal aspects of each big toe; fewer than five correct answers out of six using the thermal test instrument, which was applied in a predetermined fashion (either the warm or cold tip) on the dorsum of each foot; a score of less than eight out of 14 on the Michigan questionnaire, which was administered by the researcher to each participant. Peripheral neuropathy was defined primarily 
using the 95th percentile of age-related vibration thresholds from a local population of similar non-diabetic individuals [15]. The age-related thresholds were $7.17 \mu \mathrm{m}$ ( $45-50$ years), $14.42 \mu \mathrm{m}$ (51-60 years), $30.13 \mu \mathrm{m}(61-70$ years) and $38.07 \mu \mathrm{m}$ ( $>70$ years).

Retinopathy At the time of testing, patients were invited to a retinopathy screening test at a local optometrist's (J \& J Wade, Ely, UK). Retinal photographs were taken using a Topcon (Topcon Optical, Hong Kong SAR, People's Republic of China) digital camera. Digital images were retrieved for all patients who agreed to attend the health assessment visit. Images were also available for some non-attenders (12/54) and non-responders (14/52). The images were sent for independent rating using the National Screening Committee grading scheme (www.retinalscreening.nhs.uk) by a single rater unaware of study group status. Images were graded into the following categories: normal; mild background nonproliferative diabetic retinopathy (NPDR); moderate to severe NPDR; proliferative retinopathy; advanced proliferative retinopathy; maculopathy; photocoagulation; and ungradable.

Renal disease Renal disease was evaluated by measuring the ACR in a random sample of urine; threshold values were stratified by sex (microalbuminuria: male $2.0-20.0 \mathrm{mg} / \mathrm{mmol}$, female $2.8-28.0 \mathrm{mg} / \mathrm{mmol}$; overt diabetic nephropathy: male $>20.0 \mathrm{mg} / \mathrm{mmol}$, female $>28 \mathrm{mg} / \mathrm{mmol}$ ) [16].

Cardiovascular disease Cardiovascular disease was assessed using three methods: (1) self-report from the Rose angina questionnaire: a score $>3$ was defined as the presence of clinical ischaemic heart disease (IHD) [17, 18]; (2) a 12-lead ECG, which was graded using the Minnesota coding system [19]; (3) 10-year modelled risk for CHD calculated using the UK Prospective Diabetes Study (UKPDS) risk engine (calculated for individuals who did not report a prior cardiovascular disease [CVD] event) [20].

Functional status and health utility The self-report questionnaire contained the Short Form (SF)-36 [21] and the EuroQol (EQ)-5D scores [22]. The SF-36 has eight domains, yielding summary scores for physical health and mental well-being from 0 to 100 ; higher values indicate higher well-being. The EQ-5D contains a five-level descriptive system, known as the health state, and a visual analogue scale ranging from 0 (worst possible health state) to 100 (best possible health state).

Statistical analysis Characteristics of the patients with diabetes were summarised separately according to whether they were in the screened or unscreened population. Groups were compared using the unpaired $t$ test for normally distributed continuous variables, the Mann-Whitney $U$ test for non- normally distributed continuous data, and the $\chi^{2}$ test for categorical data. All analyses were completed using Stata version 9.0 (StataCorp, College Station, TX, USA).

\section{Results}

Of the 199 people with diabetes registered at the practice, $116(58 \%)$ were in the screened and $83(42 \%)$ in the unscreened population. The majority of the patients $(93 \%)$ in the screened population had been identified as having diabetes on the basis of screening, whereas only a minority $(31 \%)$ of the unscreened population were diagnosed as a result of the OGTT performed in this study. Overall $76 \%$ of people attended for the health assessment. There was no significant difference in attendance between the two groups (79\% in the screened vs $72 \%$ in the unscreened population; $p=0.25)$. There were no differences in age (67.3 vs 68.0 years; $p=0.57$ ), sex (proportion of men $53 \%$ vs $53 \%$; $p=0.95$ ), or deprivation score $(-1.4$ [2.1] vs -1.5 [1.7]; $p=0.66)$ between attenders and non-attenders, respectively. The mean (SD) duration of follow-up from the initial screening test to outcome assessment for the screened population was $11.6(0.7)$ years.

The characteristics of the people with diabetes from the screened and unscreened populations who attended the health assessment are shown in Table 1. The median duration of diabetes was significantly longer in the cases in the screened population (5.0 years) compared with those that arose in the unscreened population (1.7 years; $p=0.006$ ). There were few other differences between the two groups. The proportion of men, age at diabetes diagnosis, selfreported alcohol consumption and health service use was similar between groups. The mean age (SD) of patients differed significantly: 68.3 (7.0) years in the cases from the screened population and 66.4 (6.6) in those from the unscreened population ( $p=0.048)$.

Clinical characteristics There were no differences in mean $\mathrm{HbA}_{1 \mathrm{c}}$, BMI, body fat, blood pressure and TC:HDL ratio between the diabetes cases from the screened and unscreened populations.

Prescribed medication The proportion of patients prescribed lipid-lowering, antihypertensive, hypoglycaemic medication, antidepressant or anxiolytic drugs was similar in the two groups. Compared with the cases from the screened population, a larger proportion of those in the unscreened population was prescribed antiplatelet medication $(p=0.002)$.

Peripheral vascular disease The mean (SD) ABPI was significantly lower in the cases in the screened (1.17 [0.19]) compared with the unscreened population (1.24 [0.14]; 
Table 1 Characteristics of people with diabetes from the screened and unscreened populations in the Ely cohort

\begin{tabular}{|c|c|c|c|}
\hline Characteristic & Screened population $(n=92)$ & Unscreened population $(n=60)$ & $p$ value $^{\mathrm{a}}$ \\
\hline Age (years) & $68.3(7.0)$ & $66.4(6.6)$ & 0.048 \\
\hline Male, $n(\%)$ & $61(52.6)$ & $45(54.2)$ & 0.8 \\
\hline Age at diabetes diagnosis, years & $63.6(7.4)$ & $63.6(7.7)$ & 1.0 \\
\hline Median diabetes duration (IQR), years & $5.0(1.1-10.2)$ & $1.7(0.8-4.6)$ & 0.006 \\
\hline Current smoker, $n(\%)$ & $8(14.3)$ & $11(27.5)$ & 0.11 \\
\hline Median alcohol consumption (IQR), units/week & $0(0-3)$ & $0(0-3)$ & 0.96 \\
\hline Townsend score ${ }^{\mathrm{b}}$ & $-1.4(2.1)$ & $-1.5(1.7)$ & 0.66 \\
\hline Median no. visits to GP in previous year (IQR) & $2(2-5)$ & $3(1-5)$ & 0.7 \\
\hline Median no. visits to nurse in previous year (IQR) & $2(1-4)$ & $2(2-4)$ & 0.2 \\
\hline \multicolumn{4}{|l|}{ Clinical characteristics } \\
\hline $\mathrm{HbA}_{1 \mathrm{c}}(\%)$ & $7.0(1.7)$ & $7.4(1.6)$ & 0.22 \\
\hline $\mathrm{HbA}_{1 \mathrm{c}}(\mathrm{mmol} / \mathrm{l})$ & $53(19)$ & $57(18)$ & 0.22 \\
\hline BMI $\left(\mathrm{kg} / \mathrm{m}^{2}\right)$ & $30.4(5.0)$ & $29.7(4.5)$ & 0.35 \\
\hline Body fat $(\%)$ & $37.3(9.3)$ & $35.0(8.8)$ & 0.13 \\
\hline Systolic blood pressure (mmHg) & $133(14)$ & $131(14)$ & 0.41 \\
\hline Diastolic blood pressure $(\mathrm{mmHg})$ & $80(10)$ & $79(9)$ & 0.46 \\
\hline TC/HDL-cholesterol ratio & $4.0(1.3)$ & $4.2(1.0)$ & 0.41 \\
\hline \multicolumn{4}{|l|}{ Self-reported medication, $n(\%)$} \\
\hline Lipid-lowering drugs & $30(33.0)$ & $20(32.3)$ & 0.93 \\
\hline Antihypertensive drugs & $46(50.5)$ & $37(59.7)$ & 0.27 \\
\hline Glucose-lowering drugs & $33(36.3)$ & $24(38.7)$ & 0.76 \\
\hline Antiplatelet drugs & $29(31.9)$ & $35(56.5)$ & 0.002 \\
\hline Antidepressant drugs & $4(4.4)$ & $2(3.2)$ & 0.71 \\
\hline Anxiolytic drugs & $1(1.1)$ & $1(1.6)$ & 0.78 \\
\hline \multicolumn{4}{|l|}{ Microvascular complications } \\
\hline Median vibration threshold (IQR), $\mu \mathrm{m}$ & $3.6(2.2-9.9)$ & $3.4(1.9-7.1)$ & 0.39 \\
\hline Median monofilament score (IQR) & $10(9-10)$ & $10(9-10)$ & 0.91 \\
\hline Median thermal instrument score (IQR) & $4(3.5-5)$ & $5(4-6)$ & 0.21 \\
\hline Median Michigan neuropathy score (IQR) & $3(2-4)$ & $3(2-4)$ & 0.61 \\
\hline Peripheral neuropathy, $n(\%)$ & $39(33.6)$ & $32(38.6)$ & 0.47 \\
\hline $\mathrm{NPDR}^{\mathrm{c}}, n(\%)$ & $11(20.8)$ & $28(35.0)$ & 0.08 \\
\hline Self-reported glaucoma, $n(\%)$ & $3(3.3)$ & $2(3.3)$ & 0.99 \\
\hline Self-reported cataract, $n(\%)$ & $12(13.3)$ & $12(19.4)$ & 0.32 \\
\hline Median ACR (IQR), mg/mmol & $0.9(0.6-2.8)$ & $1.0(0.6-2.6)$ & 0.95 \\
\hline Microalbuminuria, $n(\%)$ & $20(21.7)$ & $14(23.3)$ & 0.82 \\
\hline Overt nephropathy, $n(\%)$ & $4(4.3)$ & $1(1.7)$ & 0.37 \\
\hline \multicolumn{4}{|l|}{ CVD } \\
\hline ABPI & $1.17(0.19)$ & $1.24(0.14)$ & 0.035 \\
\hline Peripheral vascular disease, $n(\%)$ & $5(5.4)$ & $2(3.3)$ & 0.55 \\
\hline Rose questionnaire $>3, n(\%)$ & $18(19.6)$ & $8(13.3)$ & 0.32 \\
\hline Self-reported MI, $n(\%)$ & $7(7.7)$ & $8(12.9)$ & 0.29 \\
\hline Self-reported stroke, $n(\%)$ & $3(3.3)$ & $5(8.1)$ & 0.19 \\
\hline ECG-confirmed IHD, $n(\%)^{\mathrm{d}}$ & $30(33.7)$ & $28(46.7)$ & 0.11 \\
\hline 10 -Year CHD risk from UKPDS ${ }^{\mathrm{e}}$ & $0.24(0.15)$ & $0.23(0.14)$ & 0.60 \\
\hline \multicolumn{4}{|l|}{ Functional status and health utility } \\
\hline Physical function score (SF-36) & $67.2(29.4)$ & $69.6(30.7)$ & 0.64 \\
\hline Mental health score (SF-36) & $77.8(16.5)$ & $79.7(16.1)$ & 0.47 \\
\hline EQ-5D score $e^{e}$ & $0.80(0.69,1.0)$ & $0.80(0.71,1.0)$ & 0.55 \\
\hline EQ-5D visual analogue scale ${ }^{f}$ & $78(65,85)$ & $79.5(60,88)$ & 0.68 \\
\hline
\end{tabular}

All values are mean $(\mathrm{SD})$ unless otherwise indicated

Numbers may not add up to total due to missing data for some variables

${ }^{a}$ Populations were compared using the unpaired $t$ test for normally distributed continuous variables, the Mann-Whitney $U$ test for non-normally distributed continuous data, and the $\chi^{2}$ test for categorical data

${ }^{b}$ A composite measure of material deprivation based on four factors derived from the 1991 UK census

${ }^{\mathrm{c}}$ Graded retinal photos were available for 53 individuals in the screened group and 80 individuals in the unscreened group

${ }^{\mathrm{d}}$ IHD defined by Minnesota coding of ECG

${ }^{\mathrm{e}}$ Calculated only for those individuals who did not report a prior CVD event

${ }^{\mathrm{f}}$ Presented as geometric means $(95 \% \mathrm{CI})$ 
$p=0.035)$. The prevalence of peripheral vascular disease was $4.6 \%$, with no significant difference between the two groups $(p=0.55)$.

Peripheral neuropathy There was no significant difference in any measure of neuropathy between the study groups. Median vibration threshold values were similar in both groups (screened group: $3.6 \mu \mathrm{m}$ [interquartile range (IQR) 2.2-9.9]; unscreened group: $3.4 \mu \mathrm{m}$ [IQR 1.9-7.1]; $p=0.39$ ). In the cases from the screened population, 39 (34\%) individuals had peripheral neuropathy defined by age-specific vibration thresholds compared with $32(39 \%)$ individuals from the unscreened population $(p=0.47)$. Monofilament scores, thermal scores and Michigan scores were similar in both groups.

Retinopathy One hundred and thirty-three (67\%) individuals had a graded retinal photo: $53(46 \%)$ in the screened group and $80(96 \%)$ in the unscreened group. There were no differences in age, sex, or deprivation score between those who did and did not have retinopathy data. Although a greater proportion of the unscreened group had NPDR compared with the screened group, this was not statistically significant ( $35 \%$ vs $21 \%$, respectively; $p=0.08$ ). One participant in the unscreened group had proliferative retinopathy. No participants in either group were categorised as having advanced retinopathy or maculopathy; one participant in each group had photocoagulation. There was no significant difference in self-reported cataract or glaucoma between groups.

Renal disease The overall prevalence of microalbuminuria in the study population was $17.1 \% ; 2.5 \%$ had overt nephropathy, with no significant difference between the two groups ( $p=0.82$ and $p=0.37$, respectively).

Cardiovascular disease There were no significant differences between the two groups in the proportion of individuals with a score $>3$ on the Rose angina questionnaire $(p=0.32)$, or in those reporting a history of myocardial infarction (MI) or stroke. The prevalence of IHD from the ECG also did not differ between groups. The predicted 10-year CHD risk was 0.24 (SD 0.15) in cases in the screened population compared with 0.23 (SD 0.14) in the unscreened population $(p=0.60)$.

Functional status and health utility Both groups reported similar scores on the SF-36 mental and physical health summary scores, and on the EQ-5D scores.

\section{Discussion}

One of the arguments for considering screening for type 2 diabetes is the observation that there is an extended latent or preclinical phase in which people could be diagnosed and during which earlier therapy may have a beneficial longterm effect. However, estimates of the duration of this preclinical phase are uncertain and based on historical data. Changes in clinical practice with greater vigilance and earlier testing in patients suspected of having diabetes could lead to a shortening of this latent period and have implications for the potential public health impact of screening. The data from this parallel-group population-based study suggest that the lead time of screening is relatively short at 3.3 years. Although cases were detected earlier in the screened population, we were unable to detect significant differences in most clinical measures and prescribed medication between cases in the screened and unscreened groups 12 years after the commencement of a population-based screening programme. There were few differences in microvascular and macrovascular complications between the two groups. There were no significant differences in self-reported MI and stroke, and, although the prevalence of peripheral vascular disease did not differ between groups, the mean ABPI was lower in the screened than in the unscreened group. More patients in the unscreened group had NPDR, but this might have been due to chance (given the lack of statistical significance) or bias (given the differential follow-up by group for this outcome).

The duration of the latent period between disease onset and clinical diagnosis has been estimated to be between 9 and 12 years, based on back extrapolation of data relating to duration of disease and retinopathy risk [9]. Our estimate of a lead time of 3.3 years between detection by screening and clinical diagnosis is considerably shorter. One possible explanation is that since the publication of the paper by Harris et al. in 1992 [9] there has been an increased awareness in clinical practice of the high prevalence of undiagnosed diabetes, which has led to greater testing and earlier detection. The observation in the UK of a changing ratio of diagnosed to undiagnosed type 2 diabetes supports this view, as in the early 1990s the ratio was 1:1 [12] but is now reported to be closer to 2:1 [23]. However, the estimate by Harris et al. of 9-12 years related to the true point of onset of diabetes, which is not the same as the point at which it is detected by screening, especially if screening is infrequent. The period between onset and clinical diagnosis of diabetes may be long precisely because there are few clinical manifestations during this period. If this is true, it is possible that earlier detection may ultimately lead to better outcomes, even if few benefits are evident in the short term. The data from our study using a 5 -year screening interval suggest that the point of diabetes diagnosis is brought forward 3.3 years by screening. It is possible that a shorter screening interval could lengthen this lead time.

We hypothesised that health outcomes might be improved when treatment was commenced in the lead time 
between detection by screening and diagnosis in routine clinical practice. However, our findings do not support results from modelling studies suggesting that screening programmes could contribute to a reduction in CVD morbidity in screendetected patients $[8,24,25]$. Indeed, the ABPI outcome, albeit a somewhat subjective and imprecise measure, appeared to favour the unscreened group, although the clinical significance of the difference is unclear. Differences in treatment between the two groups during the relatively short lead time of 3.3 years might have been insufficient to generate differences in health outcomes within the follow-up period in this study, if at all. Data from recent trials of intensive treatment suggest that beneficial effects can be seen for microvascular outcomes in the short term, but CVD benefits are only seen with longer follow-up [26, 27]. However, our study might have been too small to demonstrate this.

Both groups reported similar EQ-5D and SF-36 scores, which were comparable to those in a nationally representative sample of healthy individuals [28]. Our finding differs from those of a Dutch population-based sample, where clinically diagnosed diabetes patients reported lower values on SF-36 subscales compared with patients with screendetected diabetes 1 year after diagnosis [29]. However, the same study reported a steady improvement in the SF-36 values of clinically diagnosed patients and this might have resulted in loss of differences over time. Our findings support the emerging position that screening for diabetes is not associated with long-term harm [2].

The lack of difference between groups in the majority of outcomes in this study might have been due to a dilution of the effect of screening from several sources. First, there is ongoing ad hoc opportunistic screening for type 2 diabetes in primary care in Britain, following recommendations from organisations such as Diabetes UK [30]. This might have reduced the impact of allocation of patients to a systematic screening and a no-screening control group. There has also been a continuing improvement in the detection and management of CVD risk factors including diabetes in UK primary care [31], a phenomenon enhanced by the Quality and Outcomes Framework system of remuneration for GPs [32]. Our data on prescribed medication support this assertion, as both groups were prescribed similar proportions of cardioprotective drugs and the mean $\mathrm{HbA}_{1 \mathrm{c}}$ in both groups was comparable to that achieved in trials using intensive treatment $[33,34]$. Further, there was no difference in health service usage between the screened and unscreened groups, suggesting that the opportunities to provide healthy lifestyle advice and prescribe medication were similar. The participation of a single practice in the study might have partly contributed to a more intensive approach to identifying people with diabetes and treating CVD risk factors early and aggressively in the unscreened population.
It is possible that the observation of no apparent benefits of screening for health outcomes could be explained by the characteristics of the patients with diabetes. Participants had blood pressure values below recommended targets to reduce the risk of cardiovascular mortality and progression of renal disease [35]; mean TC/HDL ratios for both groups fell within accepted treatment targets [36]. However, the proportion of patients prescribed cardioprotective drugs and glucose-lowering medication was much lower than in the intensive treatment arm of the Steno-2 study, an intervention which was associated with significant reductions in microvascular and macrovascular complications [33]. The prevalence of peripheral vascular disease was significantly lower than that found in population-based samples of Danish [37] and Chinese diabetic patients [38], as well as in a large, randomly sampled, population-based study of newly diagnosed diabetic patients in Australia [39].

Differential mortality between the cases from the screened and unscreened populations could have attenuated effects on outcomes attributable to screening. An examination of the mortality experience of the same cohort [40] did suggest that individuals who were invited to screening had a nonsignificant $21 \%$ lower mortality (HR $0.79,95 \%$ CI 0.63 , $1.00 ; p=0.05)$ than individuals who were not invited to screening between 1990 and 1999. However, there were relatively few deaths with diabetes noted as an underlying cause (6\%); and, although this does not exclude the possibility of coding errors [41], mortality is unlikely to account for the lack of differences between the cases from the screened and unscreened populations.

More people were identified with diabetes in the screened group than in the unscreened group. As plasma glucose is an inherently variable outcome, the more frequently it is assessed the greater the chance that a single value will exceed a diagnostic threshold. It is therefore possible that screening might identify 'extra' cases that may otherwise resolve on their own in the absence of screening. Other reasons for the greater number of people with diabetes in the screened group include the fact that fewer people attended for testing in the unscreened group. Furthermore, as mortality was higher initially in the unscreened group [40], some of those dying prematurely might have had undiagnosed diabetes.

Strengths and limitations The Ely cohort is a populationbased cohort with long-term follow-up. We assessed health outcomes using standardised equipment and protocols, and validated questionnaires, with trained staff unaware of study group allocation. There was a high attendance rate for the health assessment, with no differences in baseline characteristics between attenders and non-attenders. The loss to follow-up due to death or change of practice after the screening programme might have been a source of bias. 
However, such a possibility is limited, as we found no difference between baseline characteristics of patients still registered at their practice and those who had moved away $(6 \%)$, and a diagnosis of diabetes is unlikely to be the cause of individuals moving away. Our sample might have been fairly representative of the eastern England population, as up to $99 \%$ of people in Britain are registered with a general practice. However, the practice was less deprived than the average English practice and the study population was almost entirely Europid, which limits the generalisability of our findings. Given the higher absolute risk of diabetes and its consequences among other ethnic groups [42], the benefits of screening might be greater in these populations. Retinal photos were available for a much larger proportion of the unscreened than for the screened group, which might have introduced some bias. Individuals in the screened group experienced a longer mean duration of diabetes and might have already been attending for regular retinal examination, so might have chosen not to attend for an additional retinal screening for the purposes of this study. The modest sample size may also limit the inferences that can be drawn from this analysis. Finally, results may be due to chance given the number of statistical tests we performed.

\section{Conclusion}

People with clinically recognised incident type 2 diabetes in a population offered screening for diabetes were diagnosed on average 3.3 years earlier than those diagnosed in an unscreened population. However, we found few differences in health outcomes after 12 years of follow-up, and no evidence of long-term harm. Further evidence is needed to justify the introduction of population-based screening.

Acknowledgements We thank patients and practitioners at St Mary's Surgery, Ely, and J \& J Wade Optometrists, Ely.

Funding The Ely Study was supported by the Medical Research Council and NHS Research and Development. M. Rahman was funded by an NHS Research and Development training fellowship.

Contribution statement MR had full access to all of the data in the study and takes responsibility for the accuracy of the data analysis. MR, SHH, NJW and SJG take responsibility for the integrity of the data. SJG acts as guarantor for this paper. MR conducted the statistical analyses. All authors participated in the analysis and interpretation of data. All authors drafted the manuscript and participated in the critical revision of the manuscript for important intellectual content. All authors gave approval for publication of the final version of this manuscript.

Duality of interest The authors declare that there is no duality of interest associated with this manuscript.

\section{References}

1. International Diabetes Federation Diabetes Atlas, 4th ed 2009. IDF, Brussels

2. Simmons RK, Echouffo-Tcheugui JB, Griffin SJ (2010) Screening for type 2 diabetes: an update of the evidence. Diabetes Obes Metabol 12:838-844

3. Echouffo-Tcheugui JB, Sargeant LA, Prevost AT et al (2008) How much might cardiovascular risk be reduced by intensive therapy in people with screen-detected diabetes? Diabet Med 25:1433-1439

4. Family Heart Study Group (1994) Randomised controlled trial evaluating cardiovascular screening and intervention in general practice: principal results of British Family Heart Study. BMJ (Clinical research ed) 308:313-320

5. Imperial Cancer Research Fund OXCHECK Study Group (1995) Effectiveness of health checks conducted by nurses in primary care: final results of the OXCHECK study. BMJ (Clinical research ed) 310:1099-1104

6. Engberg M, Christensen B, Karlsmose B, Lous J, Lauritzen T (2002) General health screenings to improve cardiovascular risk profiles: a randomized controlled trial in general practice with 5year follow-up. J Fam Pract 51:546-552

7. Eborall HC, Griffin SJ, Prevost AT, Kinmonth AL, French DP, Sutton S (2007) Psychological impact of screening for type 2 diabetes: controlled trial and comparative study embedded in the ADDITION (Cambridge) randomised controlled trial. BMJ (Clinical research ed) 335:486

8. Kahn R, Alperin P, Eddy D et al (2010) Age at initiation and frequency of screening to detect type 2 diabetes: a cost-effectiveness analysis. Lancet 375:1365-1374

9. Harris MI, Klein R, Welborn TA, Knuiman MW (1992) Onset of NIDDM occurs at least 4-7 yr before clinical diagnosis. Diabetes Care 15:815-819

10. Williams DR, Wareham NJ, Brown DC et al (1995) Undiagnosed glucose intolerance in the community: the Isle of Ely Diabetes Project. Diabet Med 12:30-35

11. Forouhi NG, Luan J, Hennings S, Wareham NJ (2007) Incidence of type 2 diabetes in England and its association with baseline impaired fasting glucose: the Ely study 1990-2000. Diabet Med 24:200-207

12. Townsend P, Phillimore P, Beattie A (2004) Health and deprivation: inequality and the north. Croom Helm, London

13. Carter SA (1968) Indirect systolic pressures and pulse waves in arterial occlusive diseases of the lower extremities. Circulation 37:624-637

14. Feldman EL, Stevens MJ, Thomas PK, Brown MB, Canal N, Greene DA (1994) A practical two-step quantitative clinical and electrophysiological assessment for the diagnosis and staging of diabetic neuropathy. Diabetes Care 17:1281-1289

15. Rahman M, Griffin SJ, Rathmann W, Wareham NJ (2003) How should peripheral neuropathy be assessed in people with diabetes in primary care? A population-based comparison of four measures. Diabet Med 20:368-374

16. Canadian Diabetes Association (2008) Canadian Diabetes Association 2008 Clinical Practice Guidelines for the Prevention and Management of Diabetes in Canada. Canadian Journal of Diabetes 32

17. Rose G, McCartney P, Reid DD (1977) Self-administration of a questionnaire on chest pain and intermittent claudication. Br J Prev Soc Med 31:42-48

18. Rose GA (1965) Ischemic Heart Disease. Chest Pain Questionnaire. The Milbank Memorial Fund quarterly 43:32-39

19. Blackburn H (1969) Classification of the electrocardiogram for population studies: Minnesota code. J Electrocardiol 2:305-310 
20. Stevens RJ, Kothari V, Adler AI, Stratton IM (2001) The UKPDS risk engine: a model for the risk of coronary heart disease in type II diabetes (UKPDS 56). Clin Sci (Lond) 101:671-679

21. Ware JE SK, Kosinski M, Gandek B (1993) SF-36 Health survey. Manual and interpretation guide. The Health Institute, New England Medical Center, Boston

22. The EuroQol Group. (1990) EuroQol—a new facility for the measurement of health-related quality of life. Health policy (Amsterdam, Netherlands) 16:199-208

23. Holman N, Forouhi NG, Goyder E, Wild SH (2011) The Association of Public Health Observatories (APHO) Diabetes Prevalence Model: estimates of total diabetes prevalence for England, 2010 2030. Diabet Med 28:575-582

24. Chen TH, Yen MF, Tung TH (2001) A computer simulation model for cost-effectiveness analysis of mass screening for type 2 diabetes mellitus. Diabetes Res Clin Pract 54(Suppl 1):S37-S42

25. Goyder EC, Irwig LM (2000) Screening for type 2 diabetes mellitus: a decision analytic approach. Diabet Med 17:469-477

26. Holman RR, Paul SK, Bethel MA, Matthews DR, Neil HA (2008) 10-Year follow-up of intensive glucose control in type 2 diabetes. N Engl J Med 359:1577-1589

27. Patel A, MacMahon S, Chalmers J, ADVANCE Collaborative Group et al (2008) Intensive blood glucose control and vascular outcomes in patients with type 2 diabetes. $\mathrm{N}$ Engl J Med 358:2560-2572

28. Kind P, Dolan P, Gudex C, Williams A (1998) Variations in population health status: results from a United Kingdom national questionnaire survey. BMJ (Clinical research ed) 316:736-741

29. Adriaanse MC, Dekker JM, Spijkerman AM et al (2004) Healthrelated quality of life in the first year following diagnosis of type 2 diabetes: newly diagnosed patients in general practice compared with screening-detected patients. The Hoorn Screening Study. Diabet Med 21:1075-1081

30. Diabetes UK. Position statement. Early identification of people with type 2 diabetes. June 2006. Available from www.diabetes.org.uk/ About_us/Our_Views/Position_statements/Early_identification_of people_with_Type_2_diabetes/. Accessed 1 Feb 2011
31. Campbell SM, Roland MO, Middleton E, Reeves D (2005) Improvements in quality of clinical care in English general practice 1998-2003: longitudinal observational study. BMJ 331:1121

32. Doran T, Fullwood C, Gravelle H et al (2006) Pay-for-performance programs in family practices in the United Kingdom. N Engl J Med 355:375-384

33. Gaede P, Vedel P, Larsen N, Jensen GV, Parving HH, Pedersen O (2003) Multifactorial intervention and cardiovascular disease in patients with type 2 diabetes. N Engl J Med 348:383-393

34. Manley S (2003) Haemoglobin $\mathrm{A}_{1 \mathrm{c}}$ - a marker for complications of type 2 diabetes: the experience from the UK Prospective Diabetes Study (UKPDS). Clin Chem Lab Med 41:1182-1190

35. Tuomilehto J (2000) Controlling glucose and blood pressure in type 2 diabetes. BMJ (Clinical research ed) 321:394-395

36. Genest J, Frohlich J, Fodor G, McPherson R (2003) Recommendations for the management of dyslipidemia and the prevention of cardiovascular disease: summary of the 2003 update. CMAJ 169:921-924

37. de Fine ON, Holstein-Rathlou NH, Siersma V et al (2004) Peripheral vascular disease is associated with reduced glycosuria in newly diagnosed type 2 diabetic patients. Diabetes Metab 30:269-274

38. Thomas GN, Critchley JA, Tomlinson B, Cockram CS, Chan JC (2003) Peripheral vascular disease in type 2 diabetic Chinese patients: associations with metabolic indices, concomitant vascular disease and genetic factors. Diabet Med 20:988-995

39. Tapp RJ, Shaw JE, de Courten MP, Dunstan DW, Welborn TA, Zimmet PZ (2003) Foot complications in type 2 diabetes: an Australian population-based study. Diabet Med 20:105-113

40. Simmons RK, Rahman M, Jakes RW et al (2011) Effect of population screening for type 2 diabetes on mortality: long-term followup of the Ely cohort. Diabetologia 54:312-319

41. Morgan CL, Currie CJ, Peters JR (2000) Relationship between diabetes and mortality: a population study using record linkage. Diabetes Care 23:1103-1107

42. Forouhi NG, Merrick D, Goyder E et al (2006) Diabetes prevalence in England, 2001 - estimates from an epidemiological model. Diabet Med 23:189-197 